\title{
Choroidal folds in association with papilloedema
}

\author{
A. C. BIRD* AND M. D. SANDERS \\ From the Department of Ophthalmology, The National Hospital, Queen Square, London
}

Chorioretinal folds (striae) in the posterior fundus were reported by Birch-Hirschfeld and Siegfried (1915) in a patient with an orbital tumour, and similar cases have been reported by other authors (Lohlein, I927; Wolter and Jampel, I957; Hedges and Leopold, I959; Wolter, i 962). The folds were attributed to indentation of the globe by the orbital tumour, although similar findings may be seen with elevated orbital pressure as in thyroid ophthalmopathy (Rosen, I969) or orbital pseudotumour (personal observation). Recently there have been two reports (Norton, I969; Hyvärinen and Walsh, 1970) describing choroidal folds in patients without evidence of an orbital lesion and it was suggested that the folds had been produced by scleral contraction.

The first description of choroidal striae was that of Nettleship (1884) in a patient attending the National Hospital with papilloedema. He described parallel horizontal lines in the choroid, which were broad on the temporal side but finer and shorter on the nasal side of the disc. The patient had a left-sided space-occupying lesion with gross papilloedema progressing to atrophy and the striae were attributed to choroidal scarring following the resolution of oedema.

The present paper describes eight similar cases seen at the National Hospital which have been studied by fluorescein angiography.

\section{Case reports}

Case I, a 4r-year-old man, was referred by Dr. Kocen (Brook General Hospital, London) for fundus photography. His main complaint was of headaches for eight months which occurred in the morning, often waking him, and diminished progressively during the course of the day. Abnormal physical signs were limited to the eyes. The visual acuity was $6 / 36$ in the right eye and $6 / 12$ in the left, and there was bilateral papilloedema with numerous haemorrhages, cotton-wool spots, and dilated blood vessels on the disc surface. Fluorescein angiography confirmed these findings and demonstrated striae surrounding the optic discs on both sides.

Ventriculography demonstrated an intraventricular lesion which was removed through a frontal craniotomy and histological examination showed the tumour to be an oligodendroglioma.

Fluorescein angiography was repeated i month after removal of the tumour. Reduction of the disc swelling with involution of the dilated vessels and haemorrhages allowed better visualization of the chorioretinal folds, which were of two types (Fig. I, overleaf).

In the peripapillary region there were thin lines of diminished fluorescence with hyperfluorescent borders. These corresponded with grey lines deep to the retina on the stereoscopic colour pictures. The second type was characterized by alternating broad bands of increased and decreased fluorescence and situated some distance from the optic disc often in the macular region. Some continuity was demonstrated between the thin peripapillary folds and the broader choroidal folds at the macula. 


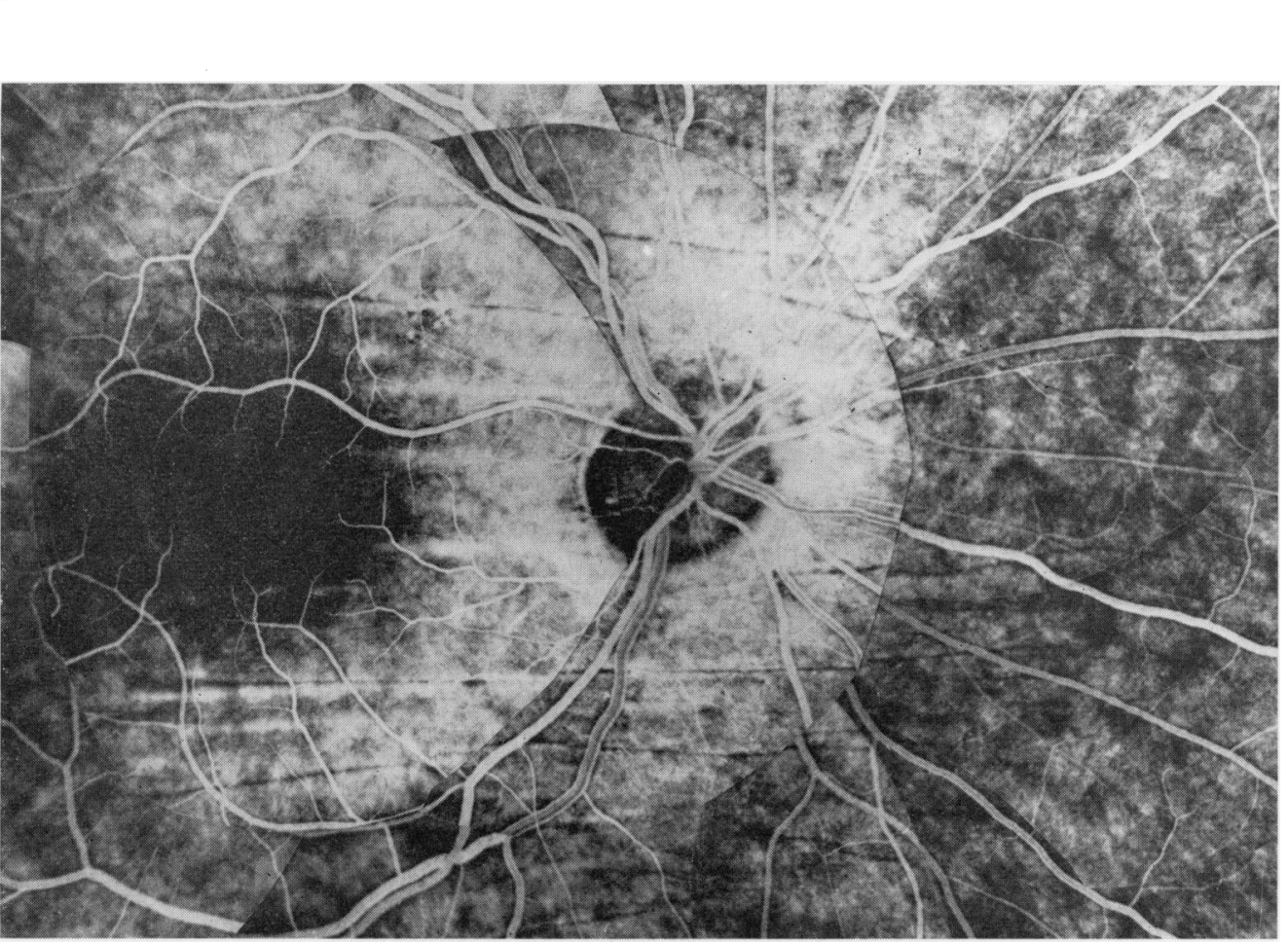
FIG. I (a) Case I. Fluorescein angiogram (right eye), showing thin linear horizontal folds with hyperfluorescengి borders

ํㅡㄹ.

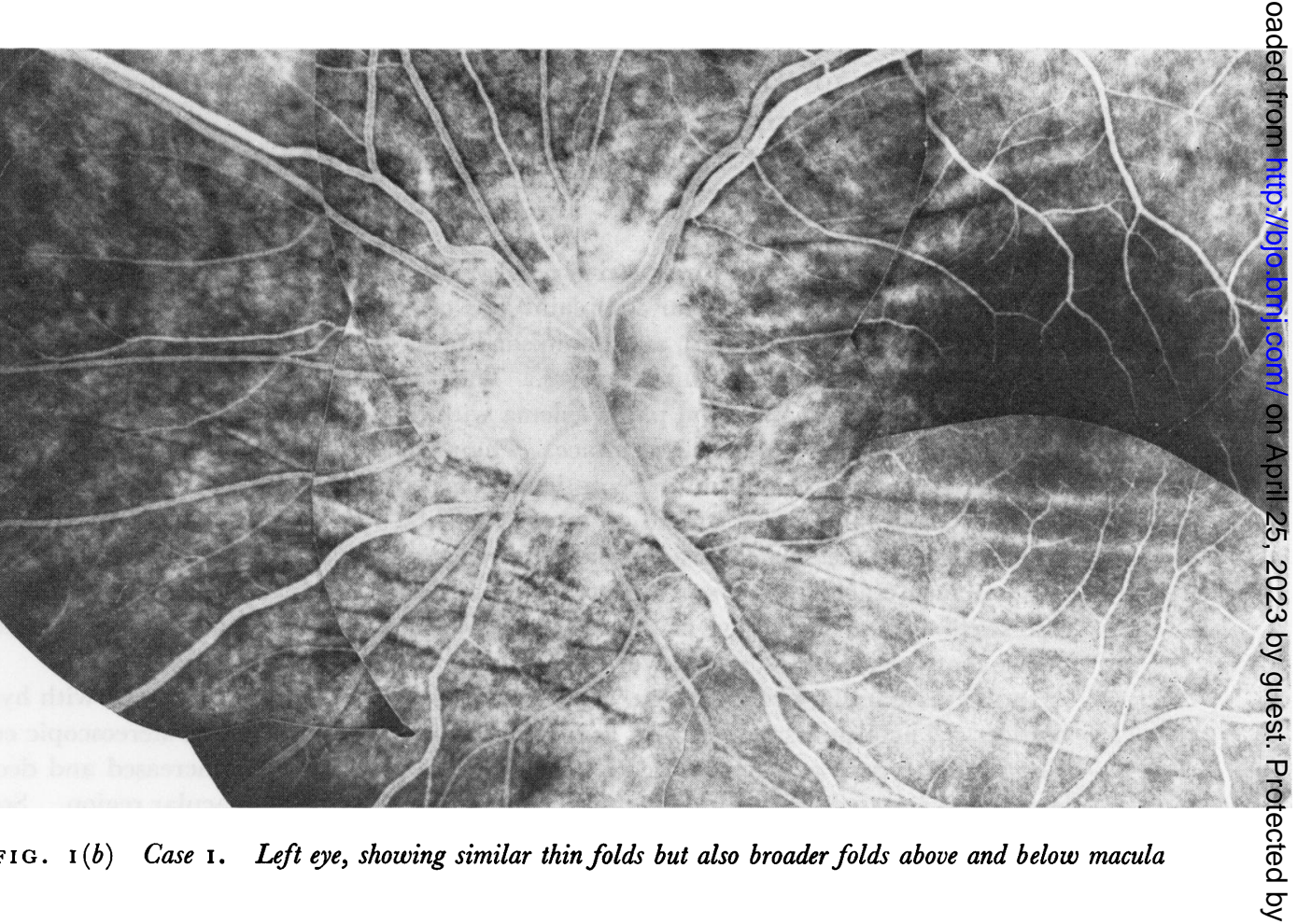




\section{Comment}

Choroidal folds were seen in a patient with severe papilloedema due to an intraventricular tumour. In the peripapillary area these folds were circular and thin, whereas in the macular region they became broader.

Case 2, a 51-year-old-woman, was referred by Dr. Hierons (Brook General Hospital, London) for fundus photography. She gave a 2-year history of blurring and distortion of vision in the right eye, and obscurations of vision in both eyes for 3 months. She had no other symptoms and abnormal physical signs were limited to her eyes.

Corrected visual acuity with each eye was $6 / 5$, there was no proptosis, and retinoscopy indicated that the hypermetropia of the right eye had increased by $0.75 \mathrm{D}$ during the previous 2 years. There was marked bilateral chronic papilloedema with superficial retinal folds concentric to the discs (Paton's folds), and broad choroidal folds were seen above the right optic disc. Fluorescein angiography showed alternate bands of increased and decreased fluorescence with the hyperfluorescent bands corresponding to the crests of the folds (Fig. 2).

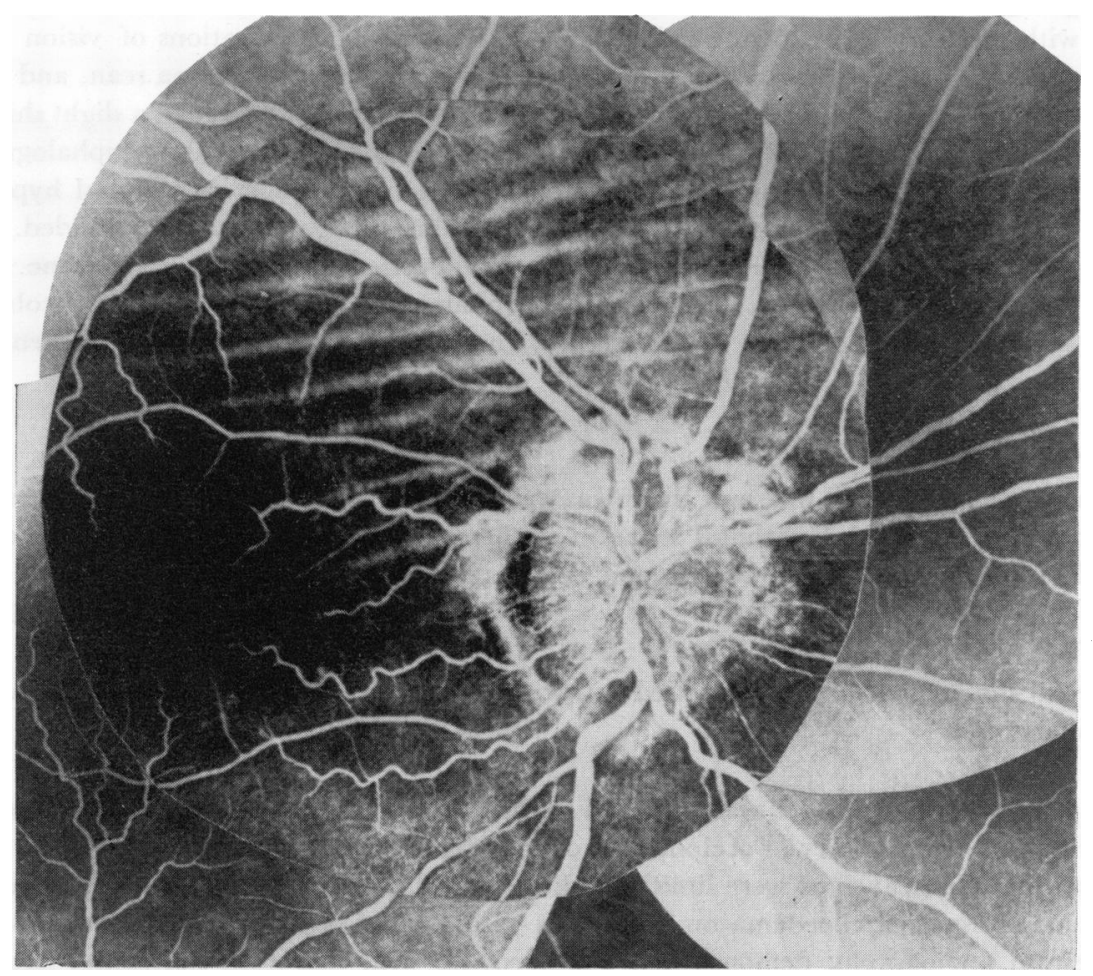

FIG. 2 Case 2. Fluorescein angiogram (right eye), showing broad horizontal choroidal folds above optic disc

Radiological studies demonstrated a space-occupying lesion in the posterior fossa. Surgical removal and subsequent histological study showed it to be a cerebellar haemangioblastoma.

Fundus photography 6 months postoperatively showed resolution of the papilloedemal although the folds remained unchanged.

\section{Comment}

A patient with chronic papilloedema due to a cerebellar haemangioblastoma had horizontal chorioretinal folds above the right disc. There had been a slight increase in the hypermetropia of this eye. 
Case 3, a 4I-year-old woman, was referred by Dr. Kocen for fundus photography with a 4-month history of progressive loss of vision in the left eye associated with intermittent throbbing headaches on the same side.

Abnormal physical signs were limited to the eyes. The visual acuity in the right eye was $6 / 5$ and? in the left $6 / 60$, and visual field testing showed a large central scotoma in the left eye. There was no proptosis and retinoscopy showed that the right eye was $\mathrm{I}$ D more hypermetropic than the left? Bilateral papilloedema was present with slight pallor of the left disc. Fluorescein angiography confirmed the papilloedema and demonstrated fine dark horizontal lines below the right optic disc $\overline{\bar{N}}$

Gamma scan and carotid angiography demonstrated a large mass at the base of the left anterion fossa; this was removed and shown to be a meningioma arising from the sphenoidal ridge.

Comment

A woman with a sphenoidal ridge meningioma had bilateral papilloedema, and choroidal folds were present in the eye contralateral to the lesion.

Case 4, a 43-year-old man, was referred by Dr. Gautier-Smith at the National Hospital in Marchiv 1967 , with a history of frequent headaches for 6 months and obscurations of vision for 2 monthsi The only abnormal sign was bilateral papilloedema. Skull $x$ rays, gamma scan, and cerebrospinapo fluid were normal. Ventriculography showed normal ventricular size, with a slight shift to the righo of the third ventricle which was confirmed by angiography. Lumbar air encephalography showed no posterior fossa abnormality, and a tentative diagnosis of benign intracranial hypertension waș made. The patient was treated with prednisone and the papilloedema subsided. During the subsequent 3 years, papilloedema recurred whenever the dose of prednisone was reducedu below $8 \mathrm{mg}$. per day. Gamma scan and air encephalography were repeated in October, 1968, and June, 1970, and the findings were unaltered. The cerebrospinal fluid pressure when last seen $320 \mathrm{~mm}$.

Ophthalmic examination July, 1970

Vision with each eye was $6 / 6$, and there was mild bilateral disc swelling. Fluorescein angiography⿳亠二口犬 demonstrated fine dark horizontal striae in both posterior poles which corresponded to fine greso lines deep to the retina in the stereoscopic colour pictures.

Comment

A 43-year-old man had chronic raised intracranial pressure causing papilloedema and associated choroidal striae.

Case 5, a 4I-year-old man, was admitted to the National Hospital in July, r97o, under Dr. R. WO Ross Russell with a history of occipital headaches during the previous 18 months.

Abnormal physical signs were limited to his eyes. The vision was $6 / 6$ with each eye, there was advanced chronic papilloedema on both sides with a chorio-retinal scar above the left optic disc 0 Fluorescein angiography demonstrated papilloedema with fine dark horizontal striae below and nasal to the right optic disc. These were deep to the retina and were thought to be pigment epio thelial folds.

Skull $x$ rays showed that the lamina dura of the dorsum sellae was eroded, and there was forward displacement of the posterior clinoids. Carotid angiography indicated enlargement of the ventricles $N$ This was confirmed by ventriculography which also demonstrated an obstruction at the junction of the third ventricle and the aqueduct of Sylvius. A diagnosis of aqueduct stenosis was made and ventriculo-atrial shunt inserted.

Comment

A 4 I-year-old man with raised intracranial pressure due to aqueduct stenosis had bilateral papill oedema and folds of the pigment epithelium in the right eve. 
Case 6, a 5I-year-old man, was referred by Dr. Roger Bannister at the National Hospital for fluorescein angiography in April, 1969, with a 2-week history of daily attacks in which he felt a rising sensation in his abdomen for about $\mathrm{I}$ minute. One such attack was followed by a generalized motor seizure. Examination of the nervous system and cerebrospinal fluid revealed no abnormalities. $\mathrm{He}$ was treated with anticonvulsants and the attacks ceased. In March, 1970, he developed headaches on the right side and visual obscurations, and examination now revealed a left facial weakness with pyramidal weakness of the left arm.

\section{Ophthalmic examination}

The visual acuity was $6 / 6$ in each eye and there was severe bilateral papilloedema with haemorrhages above the left optic disc. The visual fields showed left homonymous field loss and the blind spots were enlarged. Fluorescein appearances were typical for papilloedema, but in both eyes there were fine lines of non-fluorescence radiating from the nasal side of the disc and extending temporally $\left(\mathrm{Fi}_{3}\right.$. 3 , overleaf). Broad bands of alternating increased and decreased fluorescence were also present above the left macula.

Skull $x$ rays were normal, and the gamma scan showed increased uptake at the right base. The right middle cerebral artery was shown to be elevated by carotid angiography, and ventriculography demonstrated obliteration of the right temporal horn and displacement of the third ventricle to the left.

A malignant astrocytoma was found deep in the right temporal lobe at craniotomy.

\section{Comment}

A patient with raised intracranial pressure due to a right temporal lobe glioma had bilateral papilloedema and choroidal folds.

Case 7, a 6r-year-old man, was referred by Mr. Peter Wright for fundus photography. 3 months previously he had become confused and developed a right-sided headache, with left-sided weakness. On admission to hospital he was found to have a left homonymous hemianopia with weakness of the left arm and leg and bilateral low-grade papilloedema. Carotid angiography indicated a large avascular space-occupying lesion in the right cerebral hemisphere compatible with a haematoma. The patient made a good recovery and angiography showed resolution of the lesion, although the papilloedema persisted.

\section{Ophthalmic examination}

The visual acuity was $6 / 6$ in each eye and the left homonymous hemianopia persisted. There was bilateral chronic papilloedema more marked in the right eye than the left, and below each optic disc there were the residua of previous retinal haemorrhages. Choroidal folds were seen in both fundi. Fluorescein angiography showed these as broad bands of alternating increased and decreased fluorescence interspersed as fine dark lines (Fig. 4, overleaf) passing above and below each disc from the nasal side.

\section{Comment}

$\Lambda$ patient with papilloedema after a large intracerebral bleed had choroidal folds in both fundi.

Case 8, a 49-year-old man, was first admitted to the National Hospital in April, 1967, under the care of Dr. C. J. Earl with a 3-month history of momentary dysequilibrium which was often precipitated by head turning. He was otherwise symptom-free. He was found to have marked chronic papilloedema, but no other abnormalities were found. Skull $x$ rays and Technetium scan revealed no abnormalities and ventriculography showed no displacement, distortion, or dilatation of the ventricals. Lumbar puncture was performed and the opening cerebrospinal pressure was $230 \mathrm{~mm}$. and the fluid itself was normal. 


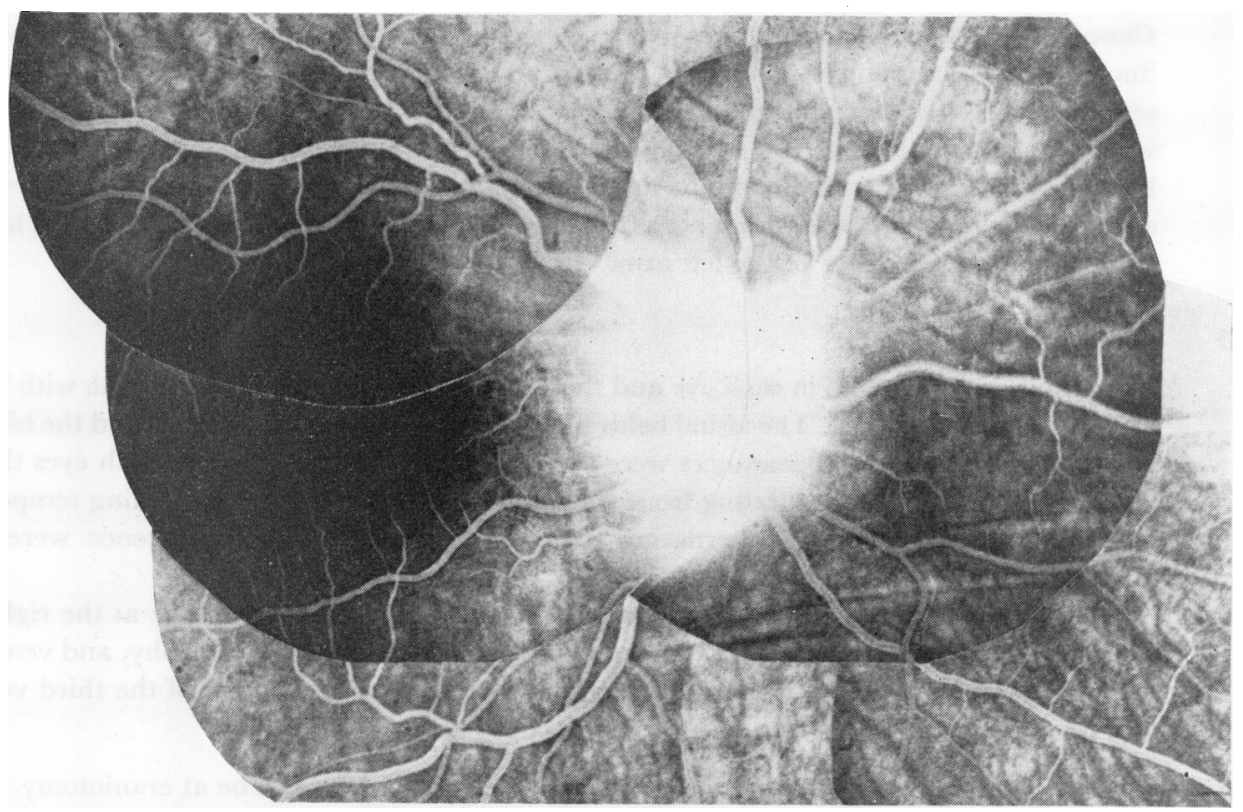

with hyperfluorescent margins ( $3 b$ showing left eye is below)

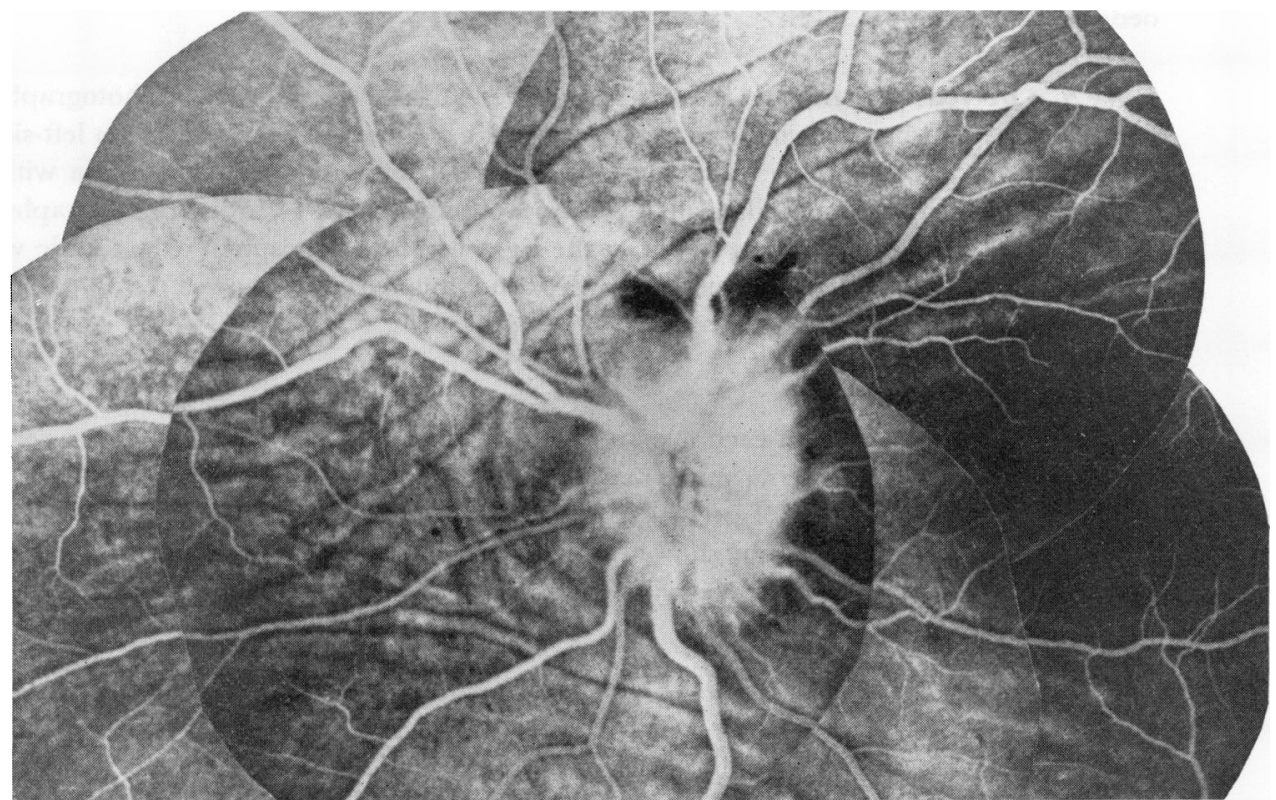

윰

FIG. $3(b)$ Case 6. Left eye, showing similar bands but with broader choroidal folds above macula

A diagnosis of benign intracranial hypertension was made and the patient was treated with systemic steroids. The symptoms resolved and the papilloedema subsided.

In December, 1970, attacks of dysequilibrium recurred and the patient was re-admitted to hospital in April, 1971. He had marked bilateral papilloedema but neurological examination revealed no other abnormalities. 


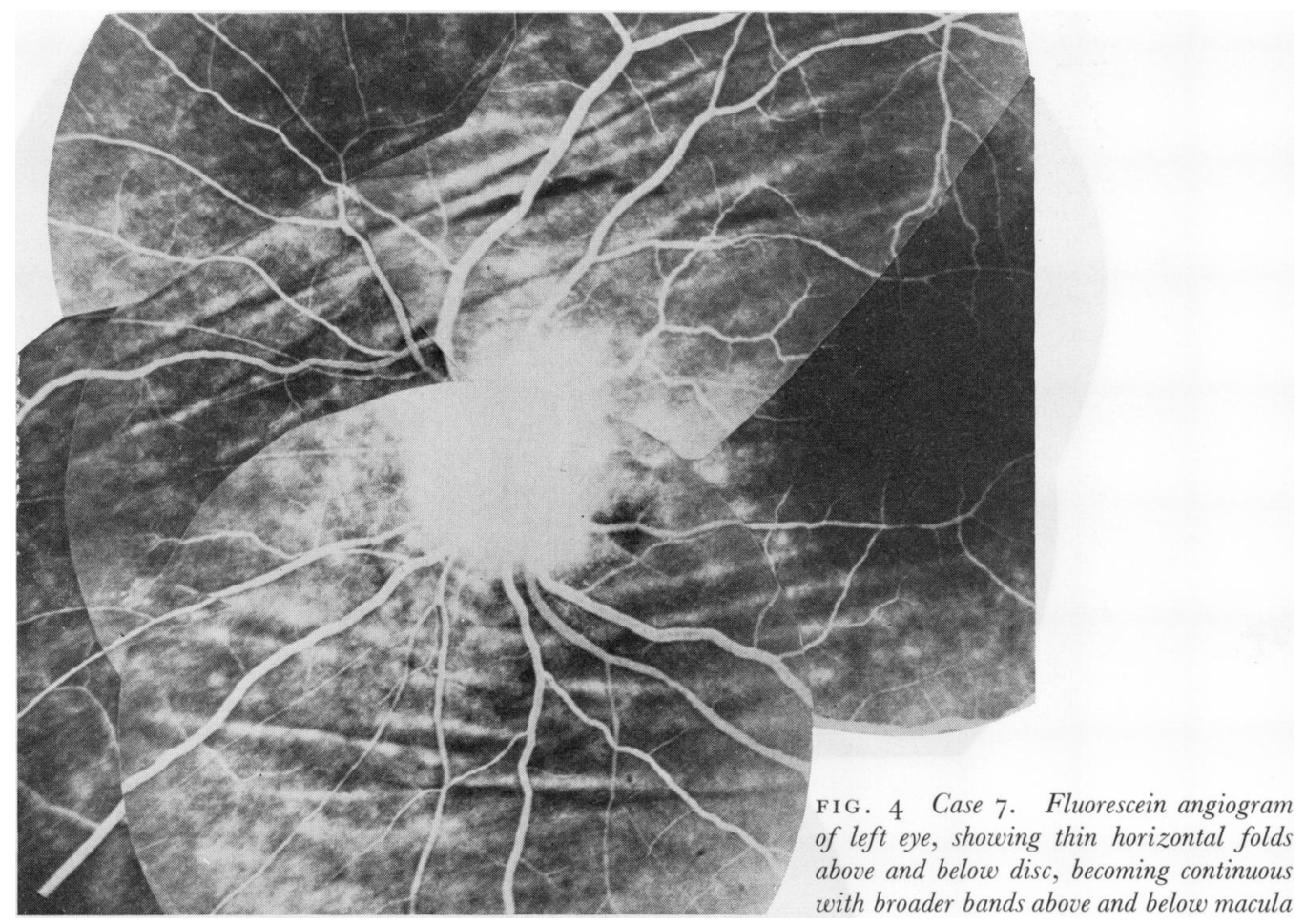

An opening pressure of $300 \mathrm{~mm}$. CSF was found on lumbar puncture, and skull $x$ rays and scan were within normal limits. The patient was treated with systemic steroids and diuretics, which produced resolution of his symptoms and regression of his papilloedema. After 9 days of treatment lumbar puncture was repeated and the opening pressure was $150 \mathrm{~mm}$.

Ophthalmic examination in April, 197 I, revealed a visual acuity of 6/6 and $\mathrm{N}_{5}$ in each eye, and the visual fields showed enlargement of the blind spots. There was marked bilateral papilloedema and choroidal folds were seen in both posterior poles. These were seen more clearly as the papilloedema resolved and were demonstrated by fluorescein angiography (Fig. 5, overleaf). The folds were horizontal in the posterior pole and tended to pass round the optic disc nasally so that in the right fundus they interdigitated on the nasal side of the disc. In the right eye the folds appeared as narrow dark lines with occasional hyperfluorescent borders. At the left macula two folds showed more marked hyperfluorescence. These were interpreted as folds in the pigment epithelium in both eyes and there were probably small ruptures in Bruch's membrane at the left macula.

\section{Comment}

A patient with benign intracranial hypertension and bilateral papilloedema had choroidal folds and ruptures in Bruch's membrane in the left macular region.

\section{Discussion}

Reports of choroidal striae have been infrequent, but easier recognition by fluorescein angiography has renewed interest in their pathogensis and diagnostic value. Their association with orbital tumours was emphasized in early reports, but recent papers (Norton, I969; Hyvärinen and Walsh, I970) have demonstrated a more diverse aetiology. The folds appear to be of two types:

(I) There are thin lines of diminished or absent fluorescence with hyperfluorescent borders which appear to be folds of the pigment epithelium and Bruch's membrane. 

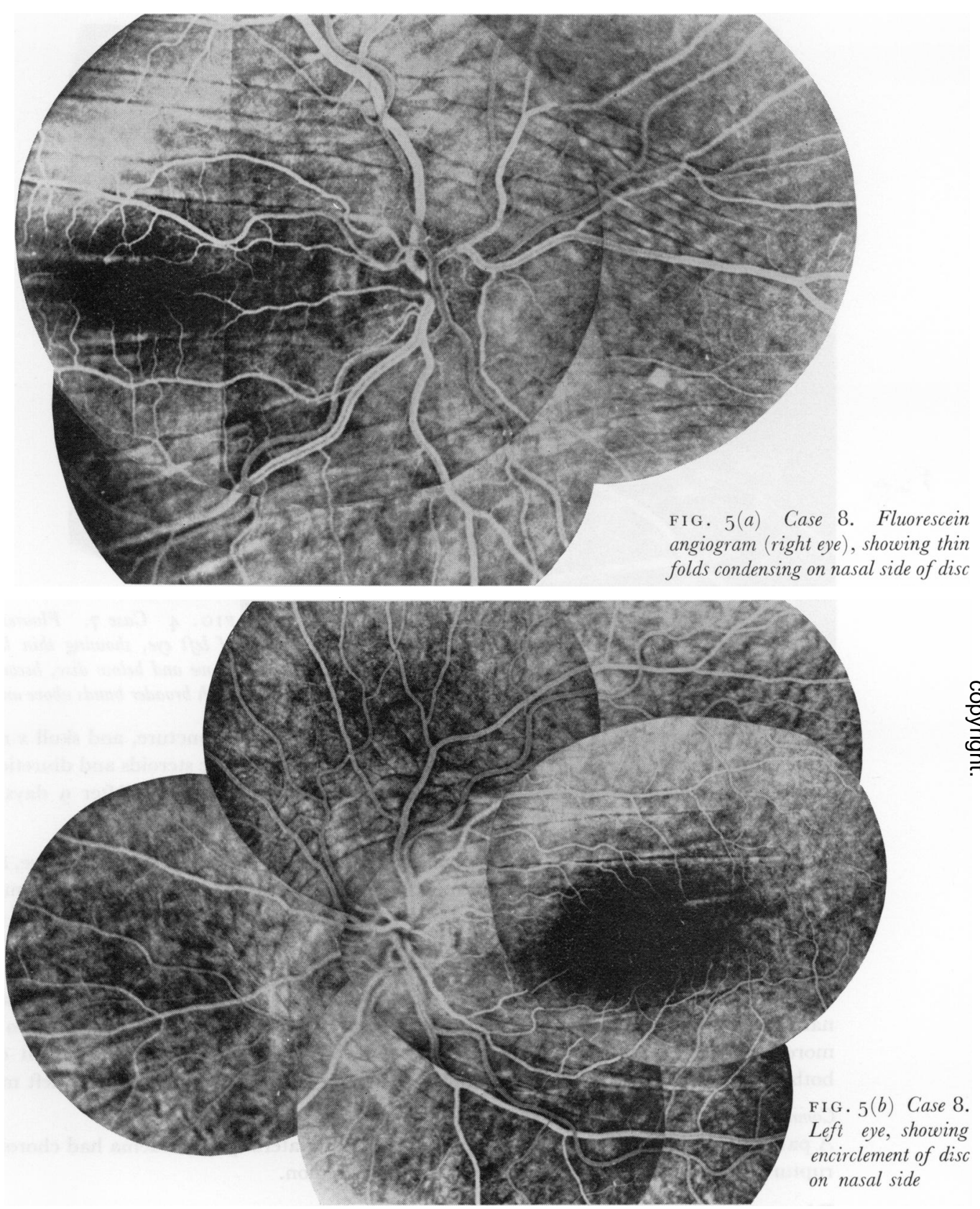

(2) There are broader alternating bands of increased and decreased fluorescence which represent full-thickness choroidal folding.

The former group occurs mainly in relation to the disc, and the latter mainly in the macular area, although the two may become continuous. Analysis suggests that the common factor in acquired choroidal striae depends on disproportion between the ocular contents and their scleral surroundings. This may be produced by space-occupying lesions within the orbit (Reese, 1963) or within the globe (Norton, I969), or by contraction of the sclera (Norton, ig69). 
Choroidal folds with papilloedema are likely to be produced by a similar disproportion. Raised intracranial pressure is accompanied by a corresponding increase in the cerebrospinal fluid pressure within the optic nerve sheaths (Paton and Holmes, I9I I). On theoretical grounds, the pressure within the sheath may be approximately twice that within the globe, and this pressure may be transmitted directly to the globe. Experimentally-induced papilloedema in dogs, and subsequent pathological study has shown a wide insertion of the dura to the sclera round the optic nerve (Leinfelder, 1959). Pathological study in humans with papilloedema shows bulbous distension of the sheath with a "leek" appearance (Paton and Holmes, I9 I I) due to the insertion of the dura close to the optic disc. Variations in this insertion may govern the formation of choroidal folds, but the distended sheath may act as a space-occupying lesion, irrespective of the site of insertion.

That raised cerebrospinal pressure may be transmitted directly to the back of the globe is supported by further evidence:

(I) A patient who presented with unilateral disc oedema due to an optic nerve sheath hygroma, was also found to have proptosis (Smith, Hoyt, and Newton, 1969). Incision of the nerve sheath resulted in resolution of the disc swelling and proptosis.

(2) Delayed filling of the peripapillary choroid has been seen in patients with papilloedema on fluorescein angiography, and produced experimentally in the owl monkey (David, 1969). It is suggested that this delayed filling is due to transmission of the cerebrospinal pressure in the optic nerve sheath to the back of the globe.

(3) Aquired hypermetropia was apparent on the side of the choroidal folds in two patients in our group, suggesting some compression of the globe.

Further mechanisms which may be contributory include scleral shrinkage as a result of impaired perfusion of the perioptic sclera, and this may account for the folds in the case described by Nettleship and in our Case I. In each of these cases severe papilloedema progressed to atrophic papilloedema and choroidal folds were more apparent after the resolution.

Lateral displacement of the choroid caused by disc swelling would seem inadequate to account for the linear pattern. Furthermore, in most cases, prominent choroidal folds were present with low grade papilloedema.

We thank the physicians and surgeons at the National Hospital for allowing us to study their cases, and Dr. Raymond Hierons and Mr. Peter Wright for referring cases for study. Miss Sue Ford performed the fluorescein angiograms and Miss Josephine Lace gave secretarial assistance.

\section{References}

BIRCh-HiRSGHFeld, A., and SIEGFRIed, C. (1915) v. Graefes Arch. Ophthal., 90, 404

DAvid, N. J. (1969) "Miami University, Neuro-Ophthalmology Symposium", vol. 5, ed. J. Lawton

Smith

HEDGES, T. R., JR., and LEOPOLD, I. H. (1969) A.M.A. Arch. Ophthal., 62, 353

HYVÄRINEN, L., and WALSH, F. B. (1970) Amer. F. Ophthal., 70, 14

LEINFELDER, P. J. (1959) Ibid., 48, 107

LOHLEIN, w. (1927) Klin. Mbl. Augenheilk., 79, 769

NETTLESHIP, E. (1884) Trans. ophthal. Soc. U.K., 4, I67

NORTon, E. W. D. (1969) Proc. roy. Soc. Med., 62, i 19

PATON, J. R., and holmes, G. (I9I I) Brain, 33, 389

REESE, A. B. (1963) "Tumors of the Eye", 2nd ed., p. 520. Harper and Row, New York

Rosen, E. S. (1969) "Fluorescence Photography of the Eye". Butterworths, London

Smith, J. L., hoYt, w. F., and Newton, т. H. (1969) Amer. F. Ophthal., 68, 633

WOLTER, J. R. (1962) Ibid., 53, 26

and JAMPEL, R. s. (1957) Klin. Mbl. Augenheilk., 131, 433 